\title{
Patient-reported outcomes in schizophrenia
}

\author{
ROSEMARIE MCCABE, MARYA SAIDI and STEFAN PRIEBE
}

\section{Background Patient-reported}

outcomes are increasingly used to evaluate

the care of people with schizophrenia.

\begin{abstract}
Aims To review established and emerging patient-reported outcomes in schizophrenia research, assessment tools and key findings.
\end{abstract}

\begin{abstract}
Method A non-systematic review addressing relevant constructs, the associated scales and key empirical findings.
\end{abstract}

Results Patient-reported outcomes in schizophrenia relate either to evaluation of illness and benefit from treatment or to resilience of the self. Of the former, needs for care, treatment satisfaction and the therapeutic relationship are most common. Less common are symptoms, insight, attitude towards medication, and clinical communication. Increasing expectations of treatment have led to new measures assessing resilience of the self, including empowerment, self-esteem, sense of coherence and recovery. Scores of different patient-related outcomes overlap and are influenced by a general tendency, largely influenced by mood, for more or less positive appraisal.

\section{Conclusions The conceptual and empirical basis for different patient- reported outcomes varies, with most data available for treatment satisfaction. More than one such outcome should be used only if there is a specific hypothesis. For new patient-reported outcomes, relative independence from existing constructs should be demonstrated.}

Declaration of Interest None.
Patient-reported outcomes are widely used in mental health research to assess treatment benefits for patients. They are defined by the United States Food and Drug Administration (2006) as 'any report coming directly from patients (i.e. study subjects) about a health condition and its treatment'. Thus, a patient-reported outcome is any outcome based on a patient's perception of a disease and its treatment(s) scored by the patient, without any interpretation by a clinician or researcher. A patient-reported outcome can be assessed through singleitem or multi-item measures and provides a means of assessing treatment benefit by capturing concepts related to how a person feels or functions with respect to their health status. We use the term patientreported outcome synonymously with subjective evaluation criterion, that is a criterion for evaluating care based on and directly reflecting the patient's views, feelings and judgements.

Since the 1970 s patient-reported outcomes have become increasingly important for the evaluation of treatment of people with schizophrenia. First, some treatment effects are known only by the patient and hence cannot be measured by observers. This is especially the case in psychiatry as most symptoms cannot be readily observed (e.g. paranoid thoughts) and are not accompanied by physical signs. Second, patients provide a unique perspective on treatment effectiveness. This is particularly important when improvements in clinical measures may not correspond to improvements in how the patient functions or feels. For example, some patients report that the sideeffects of antipsychotics are so bad that they would rather hear voices. Third, selfrated instruments might be more reliable than observer-rated measures because they eliminate interrater variability. Fourth, and probably most importantly, the use of patient-reported outcomes reflects the role of the patient as the 'consumer' of care. Although traditionally people with schizophrenia may have been treated as passive recipients of treatment, over the past five decades they have increasingly been seen as active partners in care whose views and opinions matter (Priebe et al, 1998).

From the patient perspective, capturing psychopathological symptoms only is not sufficient to reflect relevant outcomes. Improvements in outcomes related to functioning and well-being are also important dimensions of successful treatment (Fleischhacker et al, 2005). Fischer et al (2002) conducted focus groups with patients and identified six goals of treatment: increasing energy and interest; improving social relations; reducing disturbing or unusual experiences (hallucinations and delusions); reducing confusion and difficulty concentrating; reducing medication sideeffects; and increasing productive activities such as having a job. In a follow-on study of the outcome priorities of people with schizophrenia, Rosenheck et al (2005) found the strongest preference was for reducing confusion and increasing energy and the least for improving social life and reducing side-effects. However, preferences depended on patients' well-being and clinical status. Weller patients were more interested in recovery-oriented goals such as social relations, employment and personal energy whereas those who were less well were more concerned with symptoms, confusion or side-effects. Hence, patients' preferences and priorities for improvement are not uniform and depend on their current clinical status. Regardless of specific preferences, it is clear that patient-reported outcomes are increasingly accepted and used in both research and routine clinical care.

This review presents an overview of patient-reported outcomes in the context of schizophrenia. It will present the underlying constructs, the corresponding scales, touching on their psychometric properties, and key empirical findings relating to these constructs.

This review is necessarily selective owing to the burgeoning pool of relevant constructs and associated measures in mental health research. It will focus on two broad groups of outcomes: those relating to evaluation of illness and treatment and those relating to the patient's psychological well-being. Although there is no existing conceptual framework within which to classify patientrelated outcomes, the former are constructs which could be described as emanating 
from a more clinical perspective, ranging from how the patient views their illness to their perspective on the quality of care provided. The latter are more psychotherapeutic in orientation, being concerned with the well-being of the individual. Patientreported outcomes commonly used in evaluating treatment (see Table 1) are met and unmet needs for care, treatment satisfaction, and the therapeutic relationship. Less common outcomes rated by the patient, for differing reasons, are symptoms, insight, knowledge about illness/medication, medication side-effects, and the quality of clinical communication. Nasrallah et al (2005) have written about raising expectations about the prospects of functional recovery among people with schizophrenia. This is reflected in new constructs and measures in mental health research that evaluate psychological well-being of the self (see Table 2). They are shifting the emphasis from symptom management to maximising the person's quality of life, empowerment, self-esteem, sense of coherence and recovery.

\section{OUTCOMES RELATING TO ILLNESS AND TREATMENT}

\section{Needs for care}

Constructing a care plan based on assessment of an individual's needs is fundamental to community care (Brewin et al, 1987). Studies show that needs for care are often assessed quite differently by patients and mental health professionals (Hansson et al, 2001), with disagreements about the number of unmet needs and the area of need (Slade et al, 1998). This is important because unmet needs are strongly associated with quality of life (Slade et al, 1999). The most commonly used measures are the Camberwell Assessment of Need (CAN; Phelan et al, 1995) and the Camberwell Assessment of Need Short Appraisal Schedule (CANSAS; Slade et al, 1999). The CAN assesses perceived need in 22 different areas of life (e.g. accommodation, self-care, daytime activities, intimate relationships) and whether patients are currently receiving any effective help with these difficulties. It can be used to assess the perceptions of the patient, their carer and a member of staff working with them. The CANSAS is a shortened version of the CAN covering the same areas. Buhler et al (2001) reported that people with schizophrenia can validly estimate their needs, and better executive functioning may be associated with the ability to get one's needs met, increased awareness of needs, better ability to communicate needs, or more needs in certain areas. In six European countries, Kovess-Masféty et al (2006) found that on average one in four patients had needs (approximately 6 per patient) that were not adequately met by their mental health service.

\section{Treatment satisfaction}

Treatment satisfaction in schizophrenia has been used broadly to assess satisfaction with treatment as a whole and also more narrowly to assess satisfaction with antipsychotic medication. It is central to treatment adherence (Chue, 2006). Measures of treatment satisfaction include the Verona Service Satisfaction Scale (VSSS; Ruggeri \& Dell'Agnola, 1993), the Client Assessment of Treatment (Priebe et al, 1995) and the Client Satisfaction Questionnaire (CSQ; Attkisson \& Zwick, 1982). The 82-item VSSS addresses seven dimensions: overall satisfaction, professionals' skills and behaviour, information, access, efficacy, types of intervention and relative's involvement. The dimension 'professionals' skills and behaviour' appears to be the most significant contributor to satisfaction (Henderson et al, 2003). De Wilde \& Hendriks (2005) hypothesised that before-treatment selfreported and observer-rated problem severity and treatment need might have significant effects on satisfaction. No relationships were found, however, supporting the hypothesis that the CSQ is primarily influenced by treatment variables rather than patient characteristics and is thus a good indicator of quality of treatment.

In most samples and treatment settings, mean scores of satisfaction with treatment are positive, and differences between the satisfaction with distinct forms of treatment are rather small or self-evident (e.g. patients are less satisfied with restraint and seclusion on wards). This has led to criticism of the construct. Yet, it is the most commonly used patient-reported outcome, and randomised controlled trials on new treatment methods have repeatedly found statistically significant gains in satisfaction with treatment among people with schizophrenia.

Subjective response to and satisfaction with antipsychotics are important to assess because psychiatrists tend to underestimate the level of distress resulting from sideeffects (Day et al, 1998). The Drug Attitude
Inventory (DAI; Awad, 1993) is a 30 -item scale measuring subjective responses to medication (including acceptability and tolerability) which aims to understand the factors influencing adherence. A brief 10item version (DAI-10) has also been found of use (Hogan et al, 1983). Patients expressing dissatisfaction with their medication tend to have legitimate complaints such as dysphoric reactions and side-effects that have been ignored by their physicians (Hamann et al, 2005). Attitudes toward medication are predicted by insight, the therapeutic relationship with the prescriber and experience of admission (Day et al, 2005), and are associated with adherence to medication and treatment outcome (Awad, 1993).

\section{Therapeutic relationship}

Patients view the therapeutic relationship as the most important element of good psychiatric care (Johansson \& Eklund, 2003). Their views of the therapeutic relationship are generally quite positive (Priebe \& Gruyters, 1993). Empirical evidence shows that a lower degree of satisfaction is normally associated with a higher degree of observer-rated psychopathology (Neale \& Rosenheck, 1995; McCabe \& Priebe, 2003). Older patients (Draine \& Solomon, 1996) and those with more service contacts (Klinkenberg et al, 1998) tend to rate the relationship more positively. Factor analyses of therapeutic relationship scales tend to identify a large global factor accounting for most of the variance (McCabe $\&$ Priebe, 2004). Negative ratings of the helping alliance - in one study assessed by a single simple question ('Do you feel better after talking to your keyworker? Yes or no?') - have predicted subsequent hospitalisation (Priebe \& Gruyters, 1995). These findings suggest that the patientprofessional relationship might be a relevant therapeutic factor not only in psychotherapy but also in complex psychiatric treatment settings common in the care of people with schizophrenia (Priebe $\&$ Gruyters, 1993).

Most therapeutic relationship scales used in psychiatric research have been developed in psychotherapy (McCabe \& Priebe, 2004). However, the Scale to Assess the Therapeutic Relationship (STAR; McGuire-Snieckus et al, 2007) was specifically developed in the context of psychiatric treatment of people with severe mental illness using psychometric test construction principles. It has 12 items making up three 


\begin{tabular}{|c|c|c|c|c|c|}
\hline & Reference(s) & $\begin{array}{l}\text { Number } \\
\text { of items }\end{array}$ & $\begin{array}{l}\text { Number } \\
\text { of domains/ } \\
\text { sub-scales }\end{array}$ & $\begin{array}{l}\text { Estimated } \\
\text { completion } \\
\text { time, min }\end{array}$ & Psychometric properties \\
\hline $\begin{array}{l}\text { Camberwell Assessment of Need } \\
\text { (CAN) }\end{array}$ & Phelan et al (1995) & 22 & 4 & $10-15$ & High validity and reliability \\
\hline $\begin{array}{l}\text { Camberwell Assessment of Need } \\
\text { Short Appraisal Schedule (CANSAS) }\end{array}$ & Slade et al (1999) & 22 & 2 & $3-5$ & $\begin{array}{l}\text { Reasonable face validity and good } \\
\text { interrater reliability }\end{array}$ \\
\hline $\begin{array}{l}\text { Verona Service Satisfaction Scale } \\
\text { (VSSS) }\end{array}$ & $\begin{array}{l}\text { Ruggeri \& Dall'Ag- } \\
\text { nola (1993) }\end{array}$ & 82 & 7 & $20-30$ & $\begin{array}{l}\text { High interrater consistency between } \\
\text { versions, average internal consistency } \\
\text { and test-retest reliability }\end{array}$ \\
\hline $\begin{array}{l}\text { Client Satisfaction Questionnaire } \\
\text { (CSQ) }\end{array}$ & $\begin{array}{l}\text { Attkisson \& Zwick } \\
\text { (1982) }\end{array}$ & $\begin{array}{l}31,18,8,4 \text { or } 3 \\
\text { depending on } \\
\text { the version }\end{array}$ & 1 & 10 for version 8 & High internal consistency $(\alpha=0.92)$ \\
\hline Drug Attitudes Inventory (DAI) & Awad (1993) & $\begin{array}{l}30 \text { or } 10 \text { depending } \\
\text { on the version }\end{array}$ & 7 & $15-30$ for DAI-10 & $\begin{array}{l}\text { Good internal consistency and high } \\
\text { test-retest reliability }\end{array}$ \\
\hline $\begin{array}{l}\text { Scale To Assess the Therapeutic } \\
\text { Relationship (STAR) }\end{array}$ & $\begin{array}{l}\text { McGuire-Snieckus } \\
\text { et al (2007) }\end{array}$ & 12 & 3 & $5-10$ & Test-retest reliability, $r=0.76$ \\
\hline $\begin{array}{l}\text { Therapist-Patient Relationship Scale } \\
\text { with Schizophrenic Patients (TPRS) }\end{array}$ & Stark et al (1992) & 30 & & 10 & Internal consistency, $\alpha=0.4 \mathrm{I}-0.77$ \\
\hline $\begin{array}{l}\text { Working Alliance Inventory } \\
\text { (Client Version) }\end{array}$ & $\begin{array}{l}\text { Horvath \& } \\
\text { Greenberg (1989) }\end{array}$ & $\begin{array}{l}36 \text { or } 12 \text { depending } \\
\text { on the version }\end{array}$ & 3 & $\begin{array}{l}10 \text { (for 12-item } \\
\text { version) }\end{array}$ & High internal consistency $(\alpha=0.93)$ \\
\hline Helping Alliance Scale (HAS) & $\begin{array}{l}\text { Priebe \& Gruyters } \\
\text { (1993) }\end{array}$ & 6 & 1 & 5 & $\begin{array}{l}\text { Predictive validity in relation to } \\
\text { hospitalisation }\end{array}$ \\
\hline $\begin{array}{l}\text { Two-Way Communication Checklist } \\
\text { (2-COM) }\end{array}$ & Van Os et al (2002) & 20 & 2 & $10-15$ & $\begin{array}{l}\text { High internal consistency, strong } \\
\text { associations with global well-being and } \\
\text { high face validity }\end{array}$ \\
\hline $\begin{array}{l}\text { Approaches to Schizophrenia } \\
\text { Communication Scale (ASC) }\end{array}$ & Dott et al (200 I) & 18 & $\mathrm{I}$ & 10 & Not reported \\
\hline Brief Symptom Inventory (BSI) & Derogatis (1993) & 53 & 9 & $8-10$ & $\begin{array}{l}\text { High internal consistency ( } \alpha=0.7 \mathrm{I}- \\
0.85) \text {, test-retest reliability, and } \\
\text { convergent, discriminant, and } \\
\text { construct validity }\end{array}$ \\
\hline $\begin{array}{l}\text { Symptom Checklist-90-R } \\
\text { (SCL-90-R) }\end{array}$ & Derogatis (1983) & 90 & 9 & $12-15$ & $\begin{array}{l}\text { High internal consistency ( } \alpha=0.77- \\
0.90) \text { and adequate test-retest } \\
\text { reliability }\end{array}$ \\
\hline Insight Scale & $\begin{array}{l}\text { Birchwood et al } \\
\text { (1994) }\end{array}$ & 32 & 3 & $5-10$ & $\begin{array}{l}\text { High reliability coefficients, strong face } \\
\text { validity, construct validity, criterion } \\
\text { validity and concurrent validity }\end{array}$ \\
\hline $\begin{array}{l}\text { Knowledge About Schizophrenia } \\
\text { Questionnaire (KASQ) }\end{array}$ & $\begin{array}{l}\text { Ascher-Svanum } \\
\text { (1999) }\end{array}$ & 25 & 8 & $15-20$ & $\begin{array}{l}\text { High internal consistency }(\alpha=0.87) \text { and } \\
\text { test-retest reliability }\end{array}$ \\
\hline
\end{tabular}

sub-scales: positive collaboration, positive clinician input and non-supportive clinician input. Female patients rated positive clinician input more highly. Patients with higher symptom levels had lower STAR scores and rated clinicians as having more 'nonsupportive clinician input'.

The 30-item Therapist-Patient Relationship Scale with Schizophrenic Patients (Stark et al, 1992) was developed for people with schizophrenia but is limited to capturing aspects of expressed emotion. In the patient version, the patient rates how the therapist relates to them along with the therapist's therapeutic skills. The Working Alliance Inventory (WAI; Horvath \& Greenberg, 1989) was developed in psychotherapy to yield three alliance components (goal, task and bond), and has been used fairly widely in psychiatric research (Bale et al, 2006).

Finally, the Helping Alliance Scale (HAS; also referred to as the Helping Alliance Questionnaire; Priebe \& Gruyters,
1993) is a short six-item scale covering the basic elements of therapeutic relationship scales (i.e. feeling understood, respected and receiving the right care). Recently, it has been the most frequently used scale to measure the quality of the therapeutic relationship in research evaluating care of people with severe mental illness. Using the WAI and HAS, Bale et al (2006) found that patient and keyworker scores were only weakly related for assertive community treatment. 


\section{Clinical communication}

Professional-patient communication is gaining increased attention in medicine generally, but has been relatively neglected in psychiatric research (Hassan et al, 2007). Patient involvement in decisionmaking is advocated, but concerns about the feasibility of shared decision-making in the treatment of schizophrenia have been raised in relation to the patient's ability to rationally evaluate treatment options, their severe mistrust of people when they are paranoid and their attention problems (Hamann et al, 2006). Nevertheless, involving patients in their treatment, even when they are acutely ill, is feasible and has been linked with a more positive attitude to medication (Day et al, 2005) and with increased uptake of psychoeducation (Hamann et al, 2006).

Two patient-rated measures of communication, one focusing on needs and the other on side-effects of medication, appear to be useful to highlight aspects of treatment that the clinician might not be aware of or the patient is too embarrassed to raise of their own accord. The Two-Way Communication Checklist (2-COM; Van Os et $a l, 2002)$ is a 19-item self-report schedule which highlights areas of need that the patient wishes to discuss with their clinician and has been found most useful by patients with the highest care needs. Perhaps because there was very low concordance between patients and professional carers on individual needs in a naturalistic study, the 2-COM improved doctor-patient communication and led to changes in patient management in a randomised controlled trial (van Os et al, 2004).

The Approaches to Schizophrenia Communication Scale (ASC; Dott et al, 2001) assesses subjective response to medication with the aim of improving doctor-patient communication and increasing treatment adherence. Respondents identify which of 18 common side-effects of antipsychotics (e.g. difficulty sleeping, impairments in concentration, sexual dysfunction) have troubled them recently and which areas they wish to discuss further with their clinician. Dott et al (2001) found that $86 \%$ of patients found the ASC useful in communicating their problems to members of the healthcare team. Weiden \& Miller (2001) found that patients had concerns about sexual functioning without ever having complained to the clinician. When asked why, patients said they had been too embarrassed; it was easier to report this problem on a form, even though they knew that the same clinician would be reading it.

\section{Symptoms}

Self-rated symptom measures do not have a strong tradition in the treatment of schizophrenia. As people with schizophrenia have been viewed as having poor insight, the validity of their assessment of their own symptoms has been questioned. This contrasts with a stronger reliance on self-rated symptoms in depression and anxiety. None the less, some studies have used measures of self-rated symptoms. The Brief Symptom Inventory (BSI; Derogatis, 1992) was developed from the Symptom Checklist-90-R; (SCL-90-R; Derogatis, 1983) and is a 53 -item scale assessing somatisation, obsessive-compulsive behaviour, interpersonal sensitivity, depression, anxiety, hostility, phobic anxiety, paranoid ideation and psychoticism. Weak-to-moderate correlations have been reported between selfand observer-rated symptoms (Deluty et al, 1986; Fava et al, 1986). Priebe et al (1998), and Fakhoury et al (2002) found that self-rated symptoms, self-rated needs and subjective quality of life were significantly correlated in people with schizophrenia.

\section{Insight}

The term 'insight' is widely used by clinicians to describe a patient's understanding of their illness. Many definitions and assessments also incorporate attitude towards treatment, in particular, willingness to adhere to prescribed treatment. As such, it is primarily a clinician's concept and, consequently, most insight scales are rated by a clinician or independent observer. However, there are a few self-rated insight scales. The self-report Insight Scale developed by Birchwood et al (1994) assesses the three factors proposed by David (1990), namely awareness of illness, need for treatment and attribution of symptoms. Markova \& Berrios (1992) developed an insight scale that can be either observeror self-rated. They broadened the definition of insight to include not only the person's knowledge about how the disorder affects them but also how it affects their interaction with the world. Less insight is associated with more severe positive symptoms. Patients with more insight have more positive attitudes to medication (Freudenreich et al 2004). However, greater insight is also related to increased depression and poorer subjective quality of life (Karow \& Pajonk, 2006).

The Knowledge About Schizophrenia Questionnaire (Ascher-Svanum, 1999) is related to insight and is used in assessing the outcome of psychoeducation. It is a 25-item multiple choice test to assess patients' knowledge about their illness and its management. It measures patients' knowledge about the diagnosis of schizophrenia and its prevalence, aetiology, course and prognosis, knowledge about medication and its side-effects, psychological treatments, stress factors and legal issues. It meets the need to measure the impact of patient education, now prevalent partly because of the growing emphasis on psychosocial rehabilitation and patient empowerment, and helps to demonstrate a meeting of standards of care for patient education in the USA (Ascher-Svanum, 1999).

\section{PSYCHOLOGICAL WELL- BEING AND RESILIENCE OF SELF}

Patient-reported outcomes focusing on the person's psychological well-being reflect a shift from the evaluation of treatment in terms of symptom management to resilience in the face of illness and functional recovery. Constructs that have emerged in the context of schizophrenia research in the past two decades include empowerment, self-esteem, sense of coherence and recovery (Table 2 ).

\section{Empowerment}

Empowerment of patients has its origins in the USA and emphasises patients' rights to self-determination and their economic situation as consumers of services (Laugharne $\&$ Priebe, 2006). It has been suggested that there are two relevant factors: empowerment of the self (higher self-esteem and efficacy) and empowerment within the community (giving the patient greater confidence within the community) (Corrigan \& Garman, 1997). The most widely used scale, the Empowerment Scale (Rogers et al, 1997) has five distinct sub-scales: self-esteem, power, community activism, optimism and righteous anger. Age, gender, ethnicity, education, employment and number of hospital admissions were not related to empowerment. Community activism was related to greater empowerment, and use of 


\begin{tabular}{|c|c|c|c|c|c|}
\hline & Reference & $\begin{array}{l}\text { Number } \\
\text { of items }\end{array}$ & $\begin{array}{l}\text { Number } \\
\text { of domains }\end{array}$ & $\begin{array}{l}\text { Estimated } \\
\text { completion } \\
\text { time, min }\end{array}$ & Psychometric properties \\
\hline Empowerment Scale & Rogers et al (1997) & 28 & 5 & $15-20$ & High internal consistency $(\alpha=0.85)$ \\
\hline Self-Esteem Scale & Rosenberg (1965) & 10 & 2 & $5-10$ & $\begin{array}{l}\text { High scale reliability }(\alpha=0.77-0.88) \text { and high } \\
\text { test-retest correlations }(r=0.82-0.88)\end{array}$ \\
\hline Sense of Coherence Scale (SOC) & Antonovsky (1987) & 29 & 3 & $15-20$ & $\begin{array}{l}\alpha=0.70-0.95, \text { test }- \text { retest correlation } \\
\text { showed stability and ranged from } 0.69 \text { to } 0.78 \\
\text { (I year), } 0.64 \text { ( } 3 \text { years), } 0.42 \text { to } 0.45 \text { ( } 4 \text { years), } \\
0.59 \text { to } 0.67 \text { ( } 5 \text { years) to } 0.54 \text { ( } 10 \text { years) }\end{array}$ \\
\hline Mental Health Recovery Measure (MHRM) & Young \& Bullock (2003) & 30 & 8 & 15 & $\begin{array}{l}\text { High internal reliability }(\alpha=0.93) \text { and good } \\
\text { test-restest reliability }(I \text { week: } r=0.92 ; 2 \\
\text { weeks: } r=0.91)\end{array}$ \\
\hline Recovery Assessment Scale (RAS) & Giffort et al (1995) & 41 & 3 & $25-30$ & $\begin{array}{l}\text { Adequate reliability and internal consistency; } \\
\text { total score positively correlated with quality } \\
\text { of life and empowerment, negatively with } \\
\text { psychiatric symptoms }\end{array}$ \\
\hline
\end{tabular}

services to less empowerment (Rogers et al, 1997). Wowra \& McCarter (1999) found that empowerment was influenced by employment status and education level but not race, gender or age.

\section{Self-esteem}

The disparaging nature of many peoples' voices and the content of delusional beliefs may affect self-esteem. The Rosenberg SelfEsteem Scale (Rosenberg, 1965), developed in the field of psychology, is comprised of ten items about self-worth. Sörgaard et al (2002) found that self-esteem was related to mental health and, to a lesser extent, social network. Anxiety/depression and affect balance were the strongest predictors of self-esteem, and having at least one close friend was associated with positive selfesteem. Demographic characteristics played a negligible role, with only gender (female) associated with positive self-esteem. Predictably, negative evaluation of the self was found to be strongly associated with positive symptoms and also with a more critical attitude from family members (Barrowclough et al, 2003). In terms of mental health interventions, Gumley et al (2006) found that cognitive-behavioural therapy had a positive effect on self-esteem. In addition to viewing poor self-esteem as a consequence of positive symptoms, recent work also suggests a causal role for self-esteem in the development of low mood. Smith et al (2006) found that people who were more depressed and had lower self-esteem had more severe auditory hallucinations and persecutory delusions with more negative content, and were more distressed by them.

\section{Sense of coherence}

Sense of coherence refers to a personal orientation towards life, 'a way of seeing the world', which is presumed to engender and enhance one's health experience (Antonovsky, 1993). The Sense of Coherence scale (SOC; Antonovsky, 1987) has been translated into at least 33 languages and measures three factors: comprehensibility (e.g. 'Do you have very mixed-up feelings and ideas?'), manageability (e.g. 'Do you have the feeling that you're being treated unfairly?'), and meaningfulness (e.g. 'How often do you have the feeling that there's little meaning in the things you do in your daily life?') (Mlonzi, 1998). Bengtsson-Tops \& Hansson (2001) found that sense of coherence was related to mastery, self-esteem and social support, but was negatively associated with psychopathology. During an 18-month follow-up period, changes in sense of coherence were positively correlated with changes in subjective quality of life, general health, global well-being and psychosocial functioning.

\section{Recovery}

Service users and service user organisations have been active in proposing the assessment of outcomes beyond symptoms. They argue that psychological/social recovery is possible even with positive and negative symptoms, particularly when a person learns how to manage ongoing symptoms and relapses. They want to 'make the important measurable, not the measurable important' (Roberts \& Wolfson, 2004). Central to the concept of recovery is hope and leading a meaningful life.

A number of measures to assess recovery have emerged. The Mental Health Recovery Measure (MHRM; Young \& Ensing, 1999) was designed following interviews and focus groups with 18 consumers. It assesses three phases of recovery: overcoming sickness; discovering and fostering self-empowerment; and striving to attain overall well-being and reach new potentials. The Recovery Assessment Scale (RAS; Corrigan et al, 1999) is based on the narratives of service users and assesses personal confidence and hope, willingness to ask for help, goal and success orientation, reliance on others and symptom coping. Finally, Andersen et al (2006) developed the Stages of Recovery Instrument (STORI), a 50-item measure covering five stages: moratorium, awareness, preparation, rebuilding and growth. Given the relatively lengthy recovery measures, they note that 'a single, relatively short measure capturing this complex construct would prove invaluable'. Recovery has been found to be inversely related to symptoms and positively correlated with quality of life and empowerment (Corrigan et al, 1999). 


\section{PREDICTIVE VALIDITY OF SUBJECTIVE ASSESSMENT OF TREATMENT}

Alongside increasing public and political interest in patient-reported outcomes, there is a scientific basis for their assessment in evaluating illness and treatment. This stems from the role of certain subjective criteria in predicting treatment outcome. In particular, patients' ratings of satisfaction with care and the quality of the therapeutic relationship have been found to predict outcome of the treatment of schizophrenia across in- and out-patient settings. People with a more positive assessment of treatment and the therapeutic relationship tend to have a more favourable outcome (Frank \& Gunderson, 1990; Priebe \& Gruyters, 1995; Tattan \& Tarrier, 2000), including reduced symptom severity, reduced rehospitalisation, and improved quality of life and social functioning. It may be that a better therapeutic relationship leads to greater acceptance of treatment, which in turn leads to a better outcome (Chue, 2006).

\section{OVERLAP BETWEEN SUBJECTIVE EVALUATION CRITERIA}

In studies that have assessed a range of patient-reported outcomes, the subjective indicators have regularly been found to be correlated. Such correlations occur even when there is no direct item overlap. It has been suggested that there is one factor, reflecting a general tendency for more positive or negative appraisal of one's life situation, which explains more than half of the variance of constructs such as subjective quality of life, self-rated needs for care, self-rated symptoms and treatment satisfaction. Such a factor has been identified in cross-sectional and longitudinal analyses. It reflects a general appraisal tendency, and is strongly associated with patients' mood (Priebe et al, 1998; Fakhoury et al, 2002). A small number of items were sufficient to capture this general factor (Fakhoury \& Priebe, 2002; Hansson et al, 2007). Only changes in treatment satisfaction from baseline to follow-up loaded on a separate factor (Hansson et al, 2007). Similar empirical analyses have not yet been conducted on the constructs evaluating the self (self-esteem, empowerment, etc.). However, the correlations reported to date suggest that a large common factor may also account for much of the variance across these constructs.

Thus, there seems to be a mooddominated general tendency for more or less positive subjective ratings of one's situation, condition and external events. New scales may be developed in the future which are based on a new concept of subjective outcomes but still capture patient ratings and appraisals. It can be assumed that the results from such scales will also be influenced by the same general tendency. The challenge for further empirical work might be to find a simplified method for assessing the general tendency for more or less positive ratings and to capture the remaining construct-specific variance with scales whose development is closely linked to theoretical models for each construct (Hansson et al, 2007).

\section{OUTCOME MANAGEMENT}

In mental healthcare there is considerable interest in the potential for outcome management to improve clinical performance and patient care. Outcome management has been defined as a 'technology of patient experience designed to help patients, payers and providers make rational medical carerelated choices based on better insight into the effect of these choices on the patient's life' (Ellwood, 1988: p. 1551). Four factors characterise outcome management: greater use of standards and guidelines; routine assessment of patient functioning at appropriate time intervals; pooling outcome data on a massive scale; and dissemination of these results to relevant decision makers. The ultimate aim of outcome management is to improve clinical performance and patient outcomes (Smith et al, 1997).

Slade et al (2006) conducted a randomised controlled trial of routine assessment of patient-reported outcomes. Monthly postal questionnaires assessing needs, the severity of mental health problems and the therapeutic alliance were completed by patients (and staff). Patients also completed a quality of life assessment. The feedback was provided by post to patients and staff. The intervention did not improve patientreported outcomes but reduced psychiatric in-patient days. Outcomes were rated by patients outside clinical consultations and the results later made available to clinicians. Such an approach makes it difficult to know whether the outcome management process ever had an impact on how clinicians really managed their patients.
Incorporating the assessment and feedback of outcomes into routine clinical encounters so that it directly affects clinical management might make the process more meaningful for both clinicians and patients, and be more likely to improve patient outcomes.

Priebe et al (2007) conducted a randomised controlled trial of routine assessment and feedback of patient-reported outcomes in six European countries. They devised a computer-mediated intervention to structure patient-clinician dialogue (DIALOG) to be consistently patientcentred and to simultaneously assess patient outcomes. The outcomes were quality of life, needs for care, and satisfaction with treatment, all based on the patient's view at the time of the dialogue.

This procedure was designed to alter interactions so that the patient's views on their situation and needs for care were the central point of treatment discussions and the patient's view on what kind of help would improve their situation was made explicit. Patients' responses were entered onto a handheld computer/ laptop and fed back immediately in tabular and graphical screen displays for the patient and clinician to discuss together. The underlying rationale was that providing patients and clinicians with this information would lead to explicit negotiation about what the patient wanted and what the clinician could do about it. This in turn would improve subsequent care and the patient's quality of life. The intervention reduced unmet needs and increased both treatment satisfaction and subjective quality of life over a 1-year period.

\section{CONCLUSIONS}

On the basis of the evidence, incorporating subjective assessments into the treatment process itself and in treatment evaluation is warranted. Routine assessment of patient-reported outcomes (e.g. needs for care) might reduce potential discrepancy between patients and professionals, and improve outcome, although there is little empirical evidence to support this assumption at present. Structuring patientprofessional communication around the patient's view of their medication, needs or quality of life (or a combination) prior to or during the consultation might have a positive impact on treatment provision and outcome. 
In treatment evaluation, some subjective assessment of treatment is indicated because it predicts treatment outcome and it reflects the view of the 'consumer' of care. Although different constructs might appear to be conceptually distinct, there is significant empirical overlap between needs, assessment of treatment and the therapeutic relationship. This overlap reflects a general tendency, largely influenced by mood, to view one's situation positively or negatively. Of the constructs evaluating treatment, satisfaction with treatment is the outcome with the greatest evidence base, with more than 30 years of research.

The constructs that focus on selfevaluation are also overlapping. Empowerment, self-esteem and recovery are all interrelated, as are self-esteem and sense of coherence. Greater empowerment, selfesteem, sense of coherence and recovery are, in turn, associated with enhanced quality of life.

In conclusion, although the constructs might appear to be conceptually distinct, there is substantial empirical overlap. Developing a conceptual framework to classify existing and emerging patientreported outcomes might be helpful to clarifying the specific contribution of each. Despite the intuitive appeal of proposed new patient-reported outcomes, they should not be developed unless they can be shown to be sufficiently independent of existing oucomes. More than one such outcome should not be used in a single study unless there is a specific hypothesis to justify this. For the future development of patient-reported outcomes, the most pressing issues are conceptual clarity and the consideration of empirical findings, particularly the association with other outcomes.

\section{REFERENCES}

Andersen, R., Caputi, P. \& Oades, L. (2006) Stages of recovery instrument: development of a measure of recovery from serious mental illness. Australian and New Zealand Journal of Psychiatry, 40, 972-980.

Antonovsky, A. (1987) Unravelling the Mystery of Health: How People Manage Stress and Stay Well. Jossey-Bass.

Antonovsky, A. (1993) The structure and properties of the Sense of Coherence Scale. Social Science and Medicine, 36, 725-733.

Ascher-Svanum, H. (1999) Development and validation of a measure of patients' knowledge about schizophrenia. Psychiatric Services, 50, 561-563.

Attkisson, C. C. \& Zwick, R. (1982) The client satisfaction questionnaire: Psychometric properties and correlations with service utilization and psychotherapy outcome. Evaluation and Program Planning, 5, 233-237.
Awad A. G. (1993) Subjective response to neuroleptics in schizophrenia. Schizophrenia Bulletin, 19, 609-618.

Bale, R., Catty, J., Watt, H., et al (2006) Measures of the therapeutic relationship in severe psychotic illness: a comparison of two scales. International Journal of Social Psychiatry, 52, 256-266.

Barrowclough, C., Tarrier, N., Humphreys, L., et a (2003) Self-esteem in schizophrenia: relationships between self-evaluation, family attitudes, and symptomatology. Journal of Abnormal Psychology, II2 92-99.

Bengtsson-Tops, A. \& Hansson, L. (200I) Quantitative and qualitative aspects of the social network in schizophrenic patients living in the community. Relationship to sociodemographic characteristics and clinical factors and subjective quality of life. International Journal of Social Psychiatry, 47, 67-77.

Birchwood, M., Smith, J., Drury, V., et al (1994) A self-report Insight Scale for psychosis: reliability, validity and sensitivity to change. Acta Psychiatrica Scandinavica, 89, 62-67.

Brewin, C. R., Wing, J. K., Mange, S. P., et al (1987) Principles and practice in measuring needs in the longterm mentally ill: the MRC Needs for Care Assessment. Psychological Medicine, 17, 97I-98I

Buhler, J., Oades, L. G., Leicester, S. J., et al (200I) Effect of executive functioning on perceived needs in chronic schizophrenia. International Journal of Psychiatry in Clinical Practice, 5, 119-122.

Chue, P. (2006) The relationship between patient satisfaction and treatment outcomes in schizophrenia. Journal of Psychopharmacology, 20 (suppl. 6), 38-56.

Corrigan, P.W., \& Garman, A. N. (1997) Research on consumer empowerment: Methodological issues. Psychiatric Services, 48, 347-352.

Corrigan, P. W., Giffort, D., Rashid, F., et al (1999) Recovery as a psychological construct. Community Mental Health Journal, 35, 231-240.

David, A. S. (1990) Insight and psychosis. British Journal of Psychiatry, 156, 798-808.

Day, J. C., Kinderman, P. \& Bentall, R. (1998) A comparison of patients' and prescribers' beliefs about neuroleptic side-effects, prevalence, distress and causation. Acta Psychiatrica Scandinavica, 97, 93-97.

Day, J. C., Bentall, R. P., Roberts, C., et al (2005) Attitudes toward antipsychotic medication: the impact of clinical variables and relationships with health professionals. Archives of General Psychiatry, 62, 717-724.

De Wilde, E. F. \& Hendriks, V. M. (2005) The Client Satisfaction Questionnaire: psychometric properties in a Dutch addict population. European Addiction Research, II, 157-162.

Deluty, B. M., Deluty, R. H. \& Carver, C. S. (1986) Concordance between clinicians' and patients' rating of anxiety and depression as mediated by private selfconsciousness. Journal of Personal Assessment, 50 , 93-106.

Derogatis, L. R. (1983) SCL-90R Administration, Scoring and Procedures Manual. Clinical Psychometric Research.

Derogatis, L. R. (1992) The Brief Symptom Inventory (BSI): Administration, Scoring, and Procedures. Manual-II (2nd edn). Clinical Psychometric Research.

Dott, S. G., Weiden, P., Hopwood, P., et al (200I) An innovative approach to clinical communication in schizophrenia: the approaches to schizophrenia communication checklists. CNS Spectrums, 4, 333-338.

Draine, J. \& Solomon, P. (1996) Case manager alliance with clients in an older cohort. Community Mental Health Journal, 32, 125-134.
Ellwood, P. M. (1988) Shattuck lecture - outcomes management. A technology of patient experience. New England Journal of Medicine, 318, 1549-1556.

Fakhoury, W. K. H. \& Priebe, S. (2002) Subjective quality of life: its association with other constructs. International Review of Psychiatry, 14, 219-224.

Fakhoury, W. K. H., Kaiser, W., Röder-Wanner, U.U. et al (2002) Subjective evaluation: is there more than one criterion? Schizophrenia Bulletin, 28, 319-327.

Fava, G. A., Kellner, R., Sansky, J., et al (1986) Rating depression in normals and depressives: observer versus self-rating s cales. Journal of Affective Disorders, II, 29-33.

Fischer, E. P., Shumway, M. \& Owen, R. R. (2002)

Priorities of consumers, providers, and family members in the treatment of schizophrenia. Psychiatric Services, 53. 724-729.

Fleischhacker, W. W., Rabinowitz, J., Kemmler, G., et al (2005) Perceived functioning, well-being and psychiatric symptoms in patients with stable schizophrenia treated with long-acting risperidone for I year. British Journal of Psychiatry, 187, |3|-136.

Frank, A. F. \& Gunderson, J. G. (1990) The role of the therapeutic alliance in the treatment of schizophrenia. Archives of General Psychiatry, 47, 228-236.

Freudenreich, O., Cather, C., Evins, A. E., et al (2004) Attitudes of schizophrenia outpatients toward psychiatric medications: relationship to clinical variables and insight. Journal of Clinical Psychiatry, 65, 1372-1376.

Giffort, D., Schmook, A., Woody, C., et al (1995) Construction of a Scale to Measure Consumer Recovery. Illinois Office of Mental Health.

Gumley, A., Karatzias, A., Power, K., et al (2006) Early intervention for relapse in schizophrenia: impact of cognitive behavioural therapy on negative beliefs about psychosis and self-esteem. British Journal of Clinical Psychology, 45, 247-260.

Hamann, J., Cohen, R., Leucht, S., et al (2005) Do patients with schizophrenia wish to be involved in decisions about their medical treatment? American journal of Psychiatry, 162, 2382-2384.

Hamann, J., Langer, B., Winkler, V., et al (2006) Shared decision making for in-patients with schizophrenia. Acta Psychiatrica Scandinavica, II4, 265-273.

Hansson, L., Vinding, H. R., Mackeprang, T., et a (200I) Comparison of key worker and patient assessment of needs in schizophrenic patients living in the community:a Nordic multicentre study. Acta Psychiatrica Scandinavica, 103, 45-51.

Hansson, L., Bjorkman, T. \& Priebe, S. (2007) Are important patient rated outcomes in community mental health care explained by only one factor? Acta Psychiatrica Scandinavica, in press.

Hassan, I., McCabe, R. \& Priebe, S. (2007)

Professional-patient communication in the treatment of mental illness: a review. Communication and Medicine, in press.

Henderson, C., Hales, H. \& Ruggeri, M. (2003) Cross-cultural differences in the conceptualisation of patients' satisfaction with psychiatric services: content validity of the English version of the Verona Service Satisfaction Scale. Social Psychiatry and Psychiatric Epidemiology, 38, 142-148.

Hogan, T. P., Awad, A. G. \& Eastwood, R. (1983) A self-report scale predictive of drug compliance in schizophrenia: reliability and discriminative ability Psychological Medicine, 13, 177-183. 
Horvath, A. O. \& Greenberg, L. S. (1989)

Development and validation of the Working Alliance Inventory. Journal of Counseling Psychology, 64, 223-233.

Johansson, H. \& Eklund, M. (2003) Patients' opinion on what constitutes good psychiatric care. Scandinavian Journal of Caring Sciences, 17, 339-346.

Karow, A., \& Pajonk, FG. (2006) Insight and quality of life in schizophrenia: recent findings and treatment implications. Current Opinion in Psychiatry, 19 (6), 637 641 .

Klinkenberg, W. D., Cho, D. W. \& Vieweg, B. (1998) Reliability and validity of the interview and self-report versions of the BASIS-32. Psychiatric Services, 49, 12291231

Kovess-Masféty, V., Wiersma, D., Xavier, M., et al (2006) Needs for care among patients with schizophrenia in six European countries: a one-year follow-up study. Clinical Practice and Epidemiology in Mental Health, 2-22.

Laugharne, R. \& Priebe, S. (2006) Trust, choice and mental health: A literature review. Social Psychiatry and Psychiatric Epidemiology, 4I, 843-852.

Markova, I. S. \& Berrios, G. E. (1992) The assessment of insight in clinical psychiatry: a new scale. Acta Psychiatrica Scandinavica, 86, 159-164.

Mlonzi, E. N. (1998) Antonovsky's Sense of Coherence Scale and I6PF second-order factors. Social Behavior and Personality, 26, 39-50.

McCabe, R. \& Priebe, S. (2003) Are therapeutic relationships in psychiatry explained by patients' symptoms? Factors influencing patient ratings. European Psychiatry, 18, 220-225.

McCabe, R. \& Priebe, S. (2004) The therapeutic relationship in the treatment of severe mental illness: a review of methods and findings. International Journal of Social Psychiatry, 50, 115-128.

McGuire-Snieckus, R., McCabe, R., Catty, J., et al (2007) A new scale to assess the therapeutic relationship in community mental health care: STAR. Psychological Medicine, 37, 85-95.

Nasrallah, H. A., Targum, S. D., Tandon, R., et a (2005) Defining and measuring clinical effectiveness in the treatment of schizophrenia. Psychiatric Services, $\mathbf{5 6}$ 273-282

Neale, M. S. \& Rosenheck, R. A. (1995) Therapeutic alliance and outcome in a VA intensive case management program. Psychiatric Services, 46, 719-721.

Phelan, M., Slade, M., Thornicroft, G., et al (1995) The Camberwell Assessment of Need (CAN): the validity and reliability of an instrument to assess the needs of people with severe mental illness. British Journa of Psychiatry, 167, 589-595.

Priebe, S. \& Gruyters, T. (1993) The role of helping alliance in psychiatric community care - A prospective study. Journal of Nervous and Mental Disease, 18I, 552 557.

ROSEMARIE McCABE, PhD, MARYA SAIDI, MSc, STEFAN PRIEBE, MD, Department of Psychiatry, University of London, Newham Centre for Mental Health, London, UK

Correspondence: Dr Rosemarie McCabe, Unit for Social and Community Psychiatry, Newham Centre for Mental Health, Glen Road, London EI3 8SP,UK. Email: r.mccabe@qmul.ac.uk

Priebe, S. \& Gruyters, T. (1995) Patients' assessment of treatment predicting outcome. Schizophrenia Bulletin, 2I, 87-94.

Priebe, S., Gruyters, T., Heinze, M., et al (1995) Subjective criteria for evaluation of psychiatric care: methods for assessment in research and routine care. Psychiatrische Praxis, 22, 140-144.

Priebe, S., Kaiser, W., Huxley, P. J., et al (1998) Do Different subjective evaluation criteria reflect distinct constructs? Journal of Nervous and Mental Disease, 186 385-392.

Priebe, S., McCabe, R., Bullenkamp, J., et al (2007) Structured patient-clinician communication and oneyear outcome in community mental health care. A cluster randomised controlled trial. British journal of Psychiatry, in press.

Roberts, G. \& Wolfson, P. (2004) The rediscovery of recovery: open to all. Advances in Psychiatric Treatment, 10, 37-49.

Rogers, E. S., Chamberlin J., Ellison, M. L., et al (1997) A consumer-constructed scale to measure empowerment among users of mental health services. Psychiatric Services, 48, 1042-1047.

Rosenberg, M. (1965) Society and the Adolescent SelfImage. Princeton University Press.

Rosenheck, R., Stroup, S., Keefe, R. S. E., et al (2005) Measuring outcome priorities and preferences in people with schizophrenia. British Journal of Psychiatry, 187, 529-536.

Ruggeri, M. \& Dall'Agnola, R. (1993) The development and use of the Verona Expectations for Care Scale (VECS) and the Verona Service Satisfaction Scale (VSSS) for measuring expectations and satisfaction with community-based psychiatric services in patients, relatives and professionals. Psychological Medicine, 23, 5II-523.

Slade, M., Phelan, M. \& Thornicroft, G. (1998) A comparison of needs assessed by staff and by an epidemiologically representative sample of patients with psychosis. Psychological Medicine, 28, 543-550.

Slade, M., Thornicroft, G., Loftus, L., et al (1999) CAN: Camberwell Assessment of Need. A Comprehensive Needs Assessment Tool for People with Severe Mental Illness. Gaskell.

Slade, M., Leese, M., Gillard, M., et al (2006) Pre morbid IQ and response to routine outcome assessment. Psychological Medicine, 36, ||83-||9|.
Smith, G. R., Fischer, E. P., Nordquist, C. R., et al (1997) Implementing outcomes management systems in mental health settings. Psychiatric Services, 48, 364-368.

Smith, B., Fowler, D. G., Freeman, D., et al (2006)

Emotion and psychosis: links between depression, selfesteem, negative schematic beliefs and delusions and hallucinations. Schizophrenia Research, 86, |8|-188.

Sörgaard, K. W., Heikkilä, J., Hansson, L., et a (2002) Self-esteem in persons with schizophrenia. A Nordic multicentre study. Journal of Mental Health, II $405-415$

Stark, F. M., Lewandowski, G. \& Buchkremer, G. (1992) Therapist-patient relationships as a predictor of the course of schizophrenia illness. European Psychiatry, 7, $161-169$

Tattan, T. \& Tarrier, N. (2000) The expressed emotion of case managers of the seriously mentally ill: the influence of expressed emotion on clinical outcomes. Psychological Medicine, 30, 195-204.

U.S. Food and Drug Administration (2006) Guidance for Industry. Patient-Reported Outcome Measures: Use in Medical Product Development to Support Labeling Claims. FDA.

van Os, J. (2004) Does the urban environment cause psychosis? British Journal of Psychiatry, 184, 287-288.

van Os, J., Bak, M., Hanssen, M., et al (2002) Cannabis use and psychosis: a longitudinal populationbased study. American Journal of Epidemiology, I56, 319-327.

van Os, J., Altamura, A. C., Bobes, J., et al (2004) Evaluation of the Two-Way Communication Checklist as a clinical intervention. Results of a multinational, randomised controlled trial. British Journal of Psychiatry 184, 79-83.

Weiden, P. J. \& Miller, A. L. (200I) Which side effect really matter? Screening for common and distressin side effects of antipsychotic medications. Journal of Psychiatric Practice, 7, 4I-47.

Wowra, S. A. \& McCarter, R. (1999) Validation of the Empowerment Scale with an outpatient mental health population. Psychiatric Services, 50, 959-961.

Young, S. \& Bullock, W. (2003) Illness Management and Recovery and the Role of the Mental Health Recovery Measure (MHRM) in Outcomes Research. Ohio Department of Mental Health, Ohio Coordinating Center for Excellence for Illness and Recovery.

Young, S. L. \& Ensing, D. S. (1999) Exploring recovery from the perspective of people with psychiatric disabilities. Psychiatric Rehabilitation Journal, 22, 219-231. 